\title{
Wire Rupture Optimization in Wire Electrical Discharge Machining using Taguchi Approach
}

\author{
Ibrahem Maher , Ahmed A. D. Sarhan and Houriyeh Marashi \\ Center of Advanced Manufacturing and Materials Processing, Department of Mechanical Engineering, University of Malaya, Kuala Lumpur \\ 58100, Malaysia
}

\begin{abstract}
Wire electrical discharge machining (WEDM) is one of the most important nontraditional machining process that is well-known for cutting difficult to machine materials. The wire electrode along with machining parameters control the WEDM process. This research work focuses on optimizing WEDM parameters using Taguchi technique to minimize wire rupture. Experiments have been done using the L18 orthogonal array. Each experiment is repeated three times to ensure accurate readings of the wire rupture. The statistical methods of signal to noise ratio ( $\mathrm{S} / \mathrm{N}$ ratio) is applied to study effects of peak current, pulse width, charging time, wire speed, and wire tension on wire rupture. As a results, the peak current, pulse width, and wire tension have the most significant effect on wire rupture followed by charging time and wire speed. The developed analysis can be used in the metal cutting field to identify the optimum machining parameters for less wire rupture.
\end{abstract}

\section{Introduction}

Wire electrical discharge machining (WEDM) is one of the most commonly known and applied nonconventional machining processes in today's industrial practice. WEDM is used to cut any electrically conductive materials. WEDM also facilitates machining complicated shapes that cannot otherwise be achieved with conventional machining processes like turning, milling, and grinding [1]. WEDM is an electro-thermal production process, in which a thin, single-strand metal wire in conjunction with deionized water cuts through metal using heat from electrical sparks. Wire electrode is one of the most important components of cutting process in WEDM. WEDM Machining performance depends on the electrical, mechanical, physical, and geometrical properties of the wire electrode. Besides, other WEDM factors including the mechanical theory, machine intelligence, type of pulse generator, and dielectric flushing system affect machining performance.

The wire electrode is the central component of a WEDM system for the process of producing steady electrical discharge. Therefore, WEDM performance is largely affected by the wire electrode [2]. Wire rupture is a critical phenomenon that affects quality and productivity in the WEDM process. It requires some prior knowledge about the wire electrode and workpiece characteristics in the cutting process in order to avoid such ruptures for continuous process operation. Different factors lead to wire breakage, such as high wire tension, thermal load, electrical discharge impact, and poor flushing. When the developed stresses in the wire are greater than the wire strength, the wire will rupture. The stresses developing in the wire increase with changing wire properties and characteristics, reducing the cross section and increasing the wire temperature. High temperature, varying workpiece thickness, and process parameters influence the wire strength and consequently, wire rupture [3]. Lin et al. [4] developed a control strategy based on fuzzy logic to improve the machining accuracy and concentrate the sparking in the corner areas without affecting the cutting feed rates. During WEDM of pure titanium, wire breakage occurs when the wire encounters non-conducting particles. Many research works have been done on WEDM in contrast to very few investigations on the wire breakage frequency of pure titanium. Kinoshita et al. [5] analyzed the various types of wire breakage. To prevent wire breakage, they developed a control system with a means of monitoring the pulse frequency.

The majority of efforts in past decades have been directed to increasing machining speed without reducing machining accuracy while considering various processrelated constraints like wire breakage. Following a comprehensive review of published research works in this field, so far, no research has been introduced that identifies and predict the wire rupture size. Hence, the aim of this work is to obtain the best cutting parameters (peak current, pulse width, charging time, wire speed, and wire tension) for less wire rupture in WEDM process using Taguchi approach. 


\section{Methodology}

The effects of machining parameters related to power supply, wire electrode were investigated on wire rupture or wire loss $(W L)$. The parameters were peak current $(I P)$, pulse width (Ton), charging time (Toff), wire speed (WS), and wire tension $(W T)$. The machining parameter levels (Table 1) were selected from prior studies, with the working range and WEDM process parameter levels without wire breakage following the one-factor-at-a-time method.

Table 1. Levels of machining parameters

\begin{tabular}{|c|c|c|c|c|c|}
\hline \multirow{2}{*}{$\begin{array}{c}\text { Machining } \\
\text { parameter }\end{array}$} & \multirow{2}{*}{ Symbol } & \multirow{2}{*}{ Units } & \multicolumn{3}{|c|}{ Levels } \\
\cline { 4 - 6 } & & & 1 & 2 & 3 \\
\hline Peak current & $I P$ & $\mathrm{~A}$ & 16 & 17 & - \\
\hline Pulse on time & Ton & $\mu \mathrm{s}$ & 0.2 & 0.3 & 0.4 \\
\hline Pulse off time & Toff & $\mu \mathrm{s}$ & 0.5 & 0.9 & 1.3 \\
\hline Wire speed & $W S$ & $\mathrm{~m} / \mathrm{min}$ & 3 & 7 & 11 \\
\hline Wire tension & $W T$ & $\mathrm{~N}$ & 3.5 & 6 & 10.5 \\
\hline
\end{tabular}

The other machining parameters were kept constant during the experiments in order to optimize the process. The machining parameters were selected based on the literature review, experience, and machine maker's recommendations. The Taguchi L18 orthogonal array was selected because of the four machining variables with three levels each and one machining variable with two levels, as shown in Table 1.

The experiments were performed using a computer numerical control WEDM machine tool. The machine consists of four systems that are illustrated in [6]. A coated brass wire has a core of $65 \% \mathrm{Cu} 35 \% \mathrm{Zn}$ coated with a high zinc concentration layer $(40 \% \mathrm{Cu} 60 \% \mathrm{Zn}$ by weight) was used to cut The workpiece material (Ti6Al4V). The wire electrode tensile strength of 875 $\mathrm{N} / \mathrm{mm}^{2}$, Elongation of $2 \%$, and electric conductivity of $20 \%$ IACS. The electrical resistivity and thermal conductivity of Titanium alloy grade 5 (Ti6Al4V) were $17.8 \times 10-5 \Omega \cdot \mathrm{cm}$ and $6.7 \mathrm{~W} /(\mathrm{m} \cdot \mathrm{K})$ respectively.

A workpiece plate $100 \times 100 \times 20 \mathrm{~mm}$ was machined into $5 \times 5 \times 20 \mathrm{~mm}$ specimens. The wire mass loss per meter $(W L)$ was used to calculate the wire rupture. The wire mass loss per meter was calculated by weighting 10 meters of the wire electrode before and after the cutting process using a precise balancer. Then the difference in wire mass was divided by ten meters to get the mass loss per meter.

\section{Results analysis and discussion}

The average wire loss was calculated from three data recorded under the same conditions, as summarized in Table 2. The Taguchi design (L18) was selected with four machining variables with three levels and one machining variable with two levels, as shown in Table 1. The goal of the experiment is to optimize the WEDM variables to obtain low wire loss values using the smaller-is-better characteristic criteria as in the following Equation.

$$
S / N=-10 \log \left(1 / n\left(\sum y^{2}\right)\right)
$$

where $n$ is the number of experiments, and $y$ is the observed data.

Table 2 introduce the real data which used to perform this approach and show signal to noise ratios of wire loss. Table 3 present the mean $S / N$ ratios for each level of wire loss. These data were plotted as shown in Fig. 1. In this study, the $S / N$ ratio should have a maximum value to obtain optimum cutting conditions, according to the Taguchi method. Thus, the optimum cutting condition was found as $-6.56 S / N$ ratio in Table 2. The optimum cutting conditions, which were the peak current of $16 \mathrm{~A}$, the pulse width of $0.2 \mu \mathrm{s}$, the charging time of $1.3 \mu \mathrm{s}$, the wire speed of $11 \mathrm{~m} / \mathrm{min}$ and the wire tension of $10.5 \mathrm{~N}$ were obtained for the wire rupture.

Table 3 and Fig. 1 indicate that peak current, pulse width, and wire tension are more significant to the mean $S / N$ ratios to the wire rupture and charging time and wire speed have low effect on wire rupture. In addition, it is seen in Fig. 1 and Table 3 that the first level of peak current, pulse width, and charging time factors, the second level of wire speed factor, and the third level of wire tension factor are higher. And hence, the optimum machining settings determined under the same conditions for the experiments to be conducted will be $16 \mathrm{~A}$ for the peak current, $0.2 \mu \mathrm{s}$ for the pulse width, $0.5 \mu \mathrm{s}$ for the charging time, $7 \mathrm{~m} / \mathrm{min}$ for the wire speed, and $10.5 \mathrm{~N}$ for the wire tension.

Table 2. Measured $W L$ at different machining conditions

\begin{tabular}{|c|c|c|c|c|c|c|c|c|c|c|}
\hline \multirow{2}{*}{ No. } & \multicolumn{9}{|c|}{ Machining parameters } & \multicolumn{3}{|c|}{$W L(\mathrm{mg} / \mathrm{m})$} & \multirow{2}{*}{\begin{tabular}{c}
$S / N$ \\
ratios \\
\cline { 2 - 11 }
\end{tabular}} & $\begin{array}{c}\text { Ton } \\
(\mu \mathrm{s})\end{array}$ & $\begin{array}{c}\text { Toff } \\
(\mu \mathrm{s})\end{array}$ & $\begin{array}{c}W S \\
(\mathrm{~m} / \mathrm{min})\end{array}$ & $\begin{array}{c}W T \\
(\mathrm{~N})\end{array}$ & 1 & 2 & 3 & Avg. & \\
\hline 1 & 16 & 0.2 & 0.5 & 3 & 3.5 & 2.98 & 2.97 & 3.09 & 3.01 & -9.58 \\
\hline 2 & 16 & 0.2 & 0.9 & 7 & 6 & 2.28 & 2.3 & 2.16 & 2.25 & -7.03 \\
\hline 3 & 16 & 0.2 & 1.3 & 11 & 10.5 & 2.23 & 2.09 & 2.06 & 2.13 & -6.56 \\
\hline 4 & 16 & 0.3 & 0.5 & 7 & 3.5 & 2.38 & 2.34 & 2.42 & 2.38 & -7.53 \\
\hline 5 & 16 & 0.3 & 0.9 & 11 & 6 & 2.58 & 2.7 & 2.79 & 2.69 & -8.60 \\
\hline 6 & 16 & 0.3 & 1.3 & 3 & 10.5 & 4 & 4.01 & 4.22 & 4.08 & -12.21 \\
\hline 7 & 16 & 0.4 & 0.5 & 3 & 6 & 4.81 & 4.75 & 4.57 & 4.71 & -13.46 \\
\hline 8 & 16 & 0.4 & 0.9 & 7 & 10.5 & 3.76 & 3.85 & 3.89 & 3.83 & -11.67 \\
\hline 9 & 16 & 0.4 & 1.3 & 11 & 3.5 & 3.46 & 3.55 & 3.52 & 3.51 & -10.91 \\
\hline 10 & 17 & 0.2 & 0.5 & 11 & 10.5 & 2.73 & 2.84 & 2.89 & 2.82 & -9.01 \\
\hline 11 & 17 & 0.2 & 0.9 & 3 & 3.5 & 2.92 & 3.08 & 3.03 & 3.01 & -9.57 \\
\hline 12 & 17 & 0.2 & 1.3 & 7 & 6 & 2.66 & 2.53 & 2.35 & 2.51 & -8.02 \\
\hline
\end{tabular}




\begin{tabular}{|c|c|c|c|c|c|c|c|c|c|c|}
\hline 13 & 17 & 0.3 & 0.5 & 11 & 6 & 2.09 & 2.25 & 2.23 & 2.19 & -6.81 \\
\hline 14 & 17 & 0.3 & 0.9 & 3 & 10.5 & 4.31 & 4.16 & 4.25 & 4.24 & -12.55 \\
\hline 15 & 17 & 0.3 & 1.3 & 7 & 3.5 & 3.62 & 3.69 & 3.79 & 3.70 & -11.37 \\
\hline 16 & 17 & 0.4 & 0.5 & 7 & 10.5 & 8.64 & 8.49 & 8.61 & 8.58 & -18.67 \\
\hline 17 & 17 & 0.4 & 0.9 & 11 & 3.5 & 7.99 & 7.83 & 7.94 & 7.92 & -17.97 \\
\hline 18 & 17 & 0.4 & 1.3 & 3 & 6 & 11.77 & 11.86 & 12.01 & 11.88 & -21.50 \\
\hline
\end{tabular}

Table 3. Response table for $\mathrm{S} / \mathrm{N}$ ratios

\begin{tabular}{|c|c|c|c|c|c|}
\hline \multicolumn{6}{|c|}{ Response table for $S / N$ ratios of Wire loss (Smaller is better) } \\
\hline Level & $I P$ & Ton & Toff & WS & WT \\
\hline 1 & -9.729 & -8.295 & -10.845 & -11.156 & -13.145 \\
\hline 2 & -12.830 & -9.845 & -11.234 & -10.904 & -10.715 \\
\hline 3 & & -15.697 & -11.759 & -11.778 & -9.977 \\
\hline Delta & 3.101 & 7.402 & 0.914 & 0.874 & 3.168 \\
\hline Rank & 3 & 1 & 4 & 5 & 2 \\
\hline
\end{tabular}

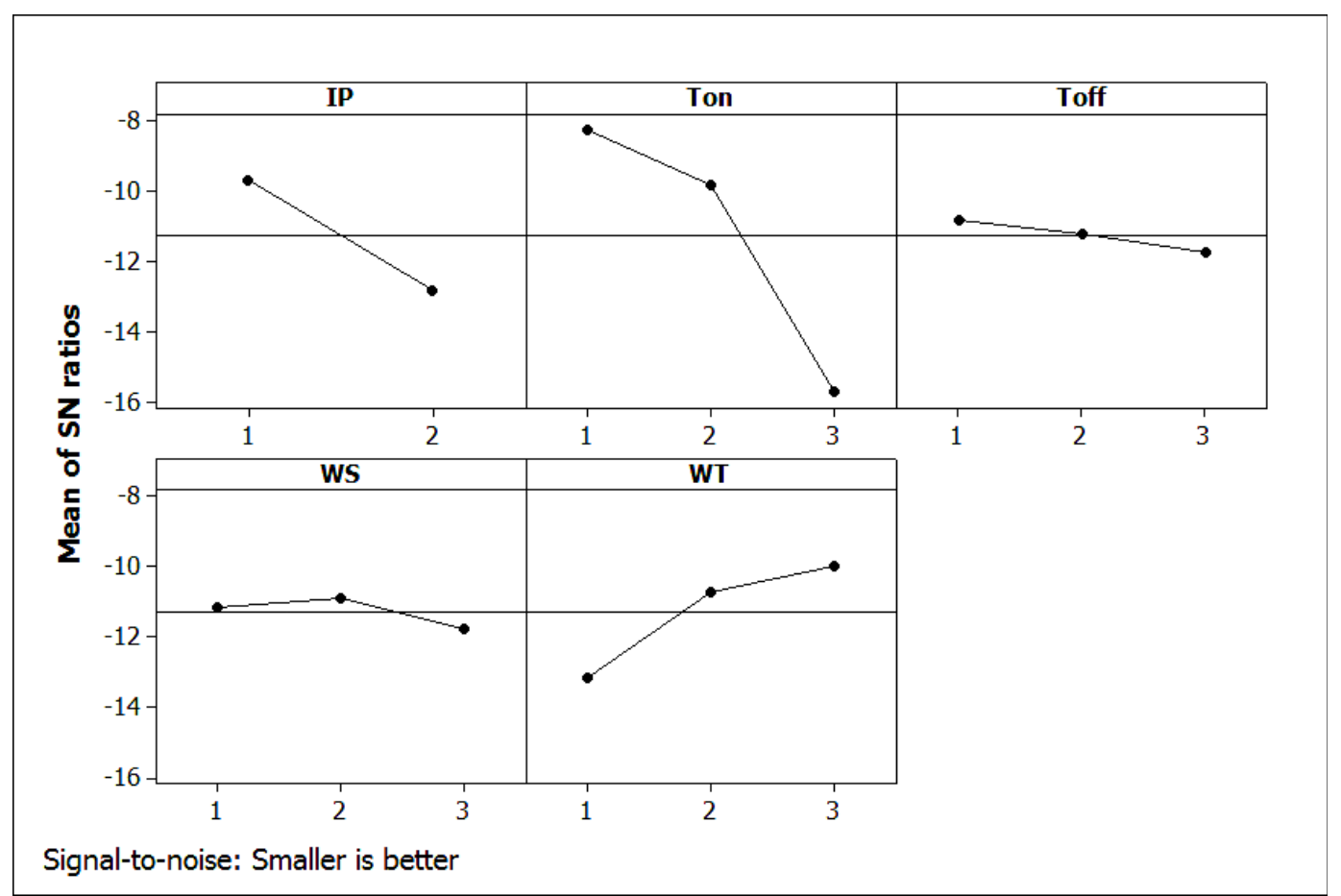

Figure 1. Effect of process parameters on $W L$

\section{Conclusion}

The Taguchi approach was used optimize machining parameters on wire electrical discharge machining process. Taguchi's L18 orthogonal array was selected for three different levels of pulse width, charging time, wire speed, and wire tension and two levels of peak current. Wire rupture' $\mathrm{S} / \mathrm{N}$ ratios was found as a result of experiments conducted according to the orthogonal array. The maximum value was found by using the $\mathrm{S} / \mathrm{N}$ ratio equation of "the smaller-the better," the maximum $\mathrm{S} / \mathrm{N}$ ratio yielded optimum cutting parameters. Optimum cutting conditions-which correspond to maximum -6.56 $\mathrm{S} / \mathrm{N}$ value of the smaller $\mathrm{WL}$ value for the smaller wire rupture in WEDM operation were found to be $16 \mathrm{~A}$ for the peak current, the pulse width of $0.2 \mu \mathrm{s}$, the charging time of $1.3 \mu \mathrm{s}$, the wire speed of $11 \mathrm{~m} / \mathrm{min}$ and the wire tension of $10.5 \mathrm{~N}$. The obtained results introduce a good knowledge that may be used in future academic and industrial research.

\section{Acknowledgement}

The authors acknowledge the financial support of The University of Malaya Postgraduate Research Grant (PPP) Program No. PG020-2013B.

\section{References}

1. I. Maher, A.A.D. Sarhan, M.M. Barzani, M. Hamdi, Increasing the productivity of the wire-cut electrical discharge machine associated with sustainable production, Journal of Cleaner Production, 108, 247255, (2015).

2. I. Maher, A.A.D. Sarhan, M. Hamdi, Review of improvements in wire electrode properties for longer 
working time and utilization in wire EDM machining, The International Journal of Advanced Manufacturing Technology, 76, 329-351, (2015).

3. Y.F. Luo, Rupture failure and mechanical strength of the electrode wire used in wire EDM, Journal of Materials Processing Technology, 94, 208-215 (1999).

4. C. T. Lin, I.F. Chung, S.-Y. Huang, Improvement of machining accuracy by fuzzy logic at corner parts for wire-EDM, Fuzzy Sets and Systems, 122, 499-511, (2001).
5. N. Kinoshita, M. Fukui, G. Gamo, Control of wireEDM preventing electrode from breaking, CIRP Annals - Manufacturing Technology, 31, 111-114, (1982).

6. I. Maher, A.A.D. Sarhan, H. Marashi, Effect of Electrical Discharge Energy on White Layer Thickness of WEDM Process, in: Reference Module in Materials Science and Materials Engineering, Elsevier, (2016). 